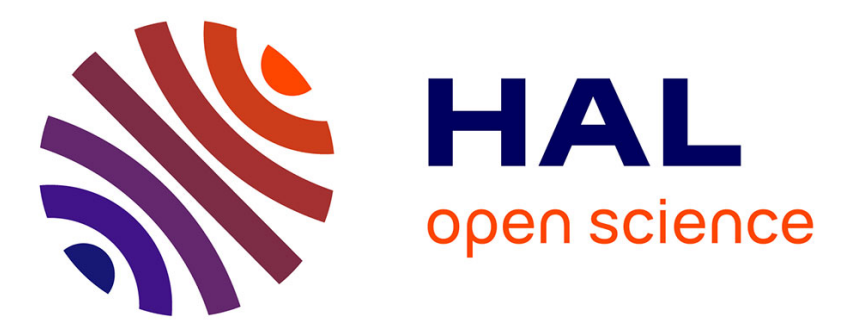

\title{
Temperature measurement of laser heated metals in highly oxidizing environment using 2D single-band and spectral pyrometry
}

Maryse Muller, Rémy Fabbro, Hazem El-Rabii, Koji Hirano

\section{To cite this version:}

Maryse Muller, Rémy Fabbro, Hazem El-Rabii, Koji Hirano. Temperature measurement of laser heated metals in highly oxidizing environment using $2 \mathrm{D}$ single-band and spectral pyrometry. Journal of Laser Applications, 2012, 24, pp.022006. 10.2351/1.3701400 . hal-01199472

\author{
HAL Id: hal-01199472 \\ https://hal.science/hal-01199472
}

Submitted on 15 Sep 2015

HAL is a multi-disciplinary open access archive for the deposit and dissemination of scientific research documents, whether they are published or not. The documents may come from teaching and research institutions in France or abroad, or from public or private research centers.
L'archive ouverte pluridisciplinaire HAL, est destinée au dépôt et à la diffusion de documents scientifiques de niveau recherche, publiés ou non, émanant des établissements d'enseignement et de recherche français ou étrangers, des laboratoires publics ou privés. 


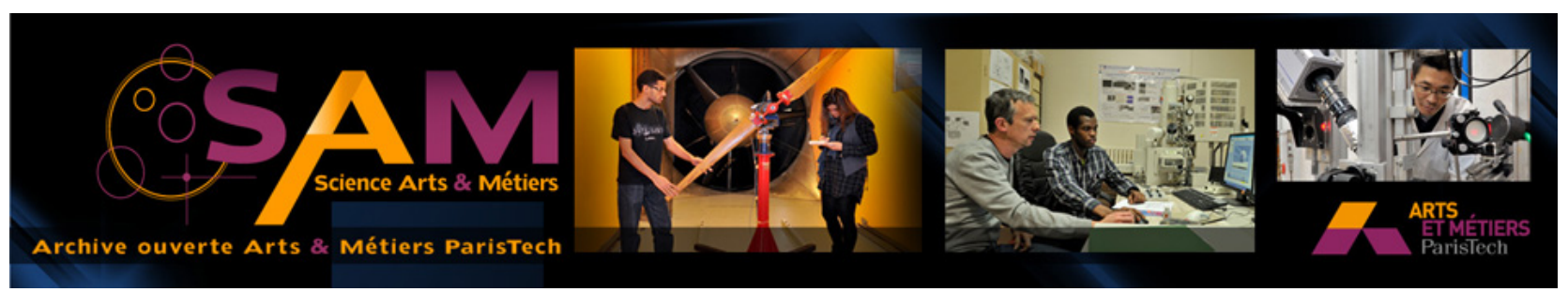

Science Arts \& Métiers (SAM)

is an open access repository that collects the work of Arts et Métiers ParisTech researchers and makes it freely available over the web where possible.

This is an author-deposited version published in: http://sam.ensam.eu

Handle ID: .http://hdl.handle.net/10985/10011

\section{To cite this version :}

Maryse MULLER, Rémy FABBRO, Hazem EL-RABII, Koji HIRANO - Temperature measurement of laser heated metals in highly oxidizing environment using 2D single-band and spectral pyrometry - Journal of Laser Applications - Vol. 24, p.022006 - 2012 


\title{
Temperature measurement of laser heated metals in highly oxidizing environment using 2D single-band and spectral pyrometry
}

\author{
Maryse Muller ${ }^{\mathrm{a})}$ and Remy Fabbro \\ PIMM Laboratory (Arts et Métiers ParisTech—CNRS), 151 Bd.de l'Hôpital, 75013 Paris, France \\ Hazem El-Rabii \\ Institut Prime, CNRS-ENSMA-Université de Poitiers, 1 Ave. Clément Ader, BP 40109, 86961 Futuroscope \\ Chasseneuil Cedex, France \\ Koji Hirano \\ Nippon Steel Corporation, Marunouchi Park Building, 2-6-1 Marunouchi, Chiyoda Ward, \\ Tokyo 100-8071, Japan
}

(Received 9 January 2012; accepted for publication 20 March 2012; published 11 April 2012)

\begin{abstract}
Calibration and validation of two temperature measurement techniques both using optical pyrometry, usable in the framework of the study of the heated metals in highly oxidizing environments and more generally during laser processing of materials in the range of 2000-4000 K have been done. The 2D single-band pyrometry technique using a fast camera provides $2 \mathrm{D}$ temperature measurement, whereas spectral pyrometry uses a spectrometer analyzing the spectra emitted by a spot on the observed surface, with uncertainties calculated to be, respectively, within $\pm 3 \%$ and $6 \%$ of the temperature. Both techniques have been used simultaneously for temperature measurement of laser heated $\mathrm{V}, \mathrm{Nb}, \mathrm{Ta}$, and $\mathrm{W}$ rods under argon and to measure the temperature of steel and iron rods during combustion under oxygen. Results obtained with both techniques are very similar and within the error bars of each other when emissivity remains constant. Moreover, spectral pyrometry has proved to be able to provide correct measurement of temperature, even with unexpected variations of the emissivity during the observed process, and to give a relevant value of this emissivity. A validation of a comsol numerical model of the heating cycle of $\mathrm{W}, \mathrm{Ta}, \mathrm{Nb}, \mathrm{V}$ rods has been obtained by comparison with the measurement. (C) 2012 Laser Institute of America.
\end{abstract}

Key words: temperature measurement, emissivity, metal combustion, laser heating

\section{INTRODUCTION}

The knowledge of temperature distribution in materials during a thermal process is of prime importance. It allows to determine the heating/cooling rates and thermal gradients that are needed to understand materials properties and behavior. In numerous applications, the very high temperatures involved prevent any possibility of measuring the temperature by direct contact approaches. For such cases, methods that use thermal emission represent an appropriate alternative as they are nonintrusive and allow measurement in harsh conditions. Nowadays, they are routinely used, for instance, in the metallurgical industry, crystallography, and in the laser materials processing. ${ }^{1-3}$ Unfortunately, standard pyrometer techniques fail to provide accurate results mainly because of the lack of knowledge about emissivity of materials and its dependence on wavelength and temperature.

Although this source of error can be significant in some situations, it is generally underestimated, if not totally neglected. ${ }^{4}$ This is especially true when one deals with the interaction of lasers with metals under an oxidizing atmosphere. The changes of phase and the appearance of metal oxides produced by the reactions preclude any reliable

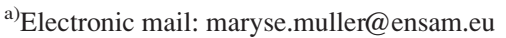

interpretation of the measured signals in the absence of data on emissivity for the main metal oxides at ambient pressure and above the melting point.

Two approaches are currently in use to circumvent this difficulty. The first one consists in using a known value of emissivity at one wavelength, or the ratio of two known values at two different wavelengths, and to assume that it does not vary with temperature. Proceeding this way has obvious limitations because such an assumption is rarely verified in practice and can lead to important measuring errors. To the best of our knowledge, this is the only approach that has been used in the study of metals combustion (see, for instance, Refs. 5-9). The second approach is to record the spectrally resolved thermal emission in the visible range and to assume some dependence of the emissivity with the wavelength. By using appropriate algorithms, it is, in principle, possible to discriminate between the variations of the thermal emission due to temperature from those resulting from the emissivity. Several examples of successful application of this method have been reported in the scientific literature. ${ }^{10-14}$ Yet, it has never been exploited to provide quantitative information on the emissivity when it is applied to laser materials interaction processes.

The purpose of this work is to show that a combination of both above-mentioned methods can provide valuable and 
complementary data for the processes occurring during laser heating of metals in a highly oxidizing atmosphere. To this end, both techniques were used, taking advantage of each of them to obtain simultaneous spatially and time-resolved temperature measurements as well as an evaluation of the emissivity: first, a fast camera provides a $2 \mathrm{D}$ cartography of the temperature (2D single-band pyrometry), and second, a spectrometer acquires spectra emitted by a spot on the sample surface, providing independent and simultaneous measurement of temperature and emissivity.

The paper is organized as follows: In Sec. II, the experimental setup is described. The theoretical background and the procedure used to calibrate each device are presented in Sec. III, along with the interpretation of the results and the evaluation of uncertainties. In Sec. IV, a comparison of the results obtained by the two techniques is presented. It concerns the laser heating of $\mathrm{V}, \mathrm{Nb}, \mathrm{Ta}$, and $\mathrm{W}$ rods in argon atmosphere and the combustion of carbon steel (CS) and pure iron rods in oxygen atmosphere. In Sec. V, a comsol Multiphysics simulation of a rod heating cycle is described and compared with corresponding experimental results. Finally, Sec. VI summarizes our conclusions.

\section{EXPERIMENTAL SETUP}

A schematic of the experimental setup is shown in Fig. 1. The metal samples studied were cylindrical rods of $3.2 \mathrm{~mm}$ in diameter and $15-25 \mathrm{~mm}$ in length. They were successively fixed in a small chuck and partly placed inside a borosilicate glass tube (with an inner diameter of $16 \mathrm{~mm}$ ), which is transparent to radiation in the wavelength range of 500-1000 nm. Argon or oxygen gas flowed out through the glass tube (at a flow rate of $40 \mathrm{l} / \mathrm{min}$ ) providing either a gas shielding to prevent oxidation during the samples heating or an oxidizing atmosphere to sustain their combustion.

The metal rod was heated up by a disk laser from Trumpf (model Trudisk 10002) operating at $1030 \mathrm{~nm}$. The laser beam was delivered through an optical fibre with a core diameter of $600 \mu \mathrm{m}$, providing a uniform intensity distribution that was

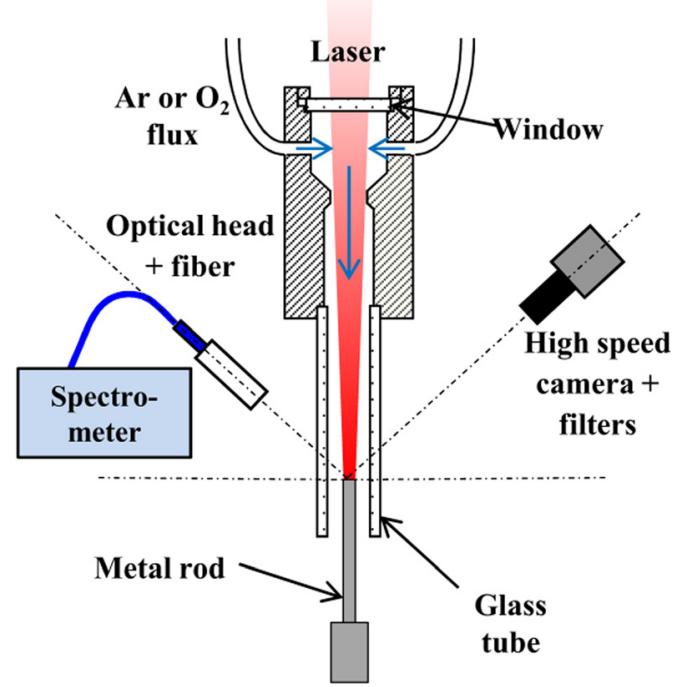

FIG. 1. Schematic of the optical pyrometry experimental setup. imaged onto the top of the rod by a set of two lenses. The circular beam spot size so obtained was $3 \mathrm{~mm}$ in diameter, which ensured a homogeneous heating of the top surface of the rod. A Photron high-speed video camera with complementary metal-oxide semiconductor (CMOS) sensors and a frame rate up to $4 \mathrm{kHz}$ was used for the $2 \mathrm{D}$ single-band pyrometry. Two optical filters (short pass $950 \mathrm{~nm}$ and long pass $800 \mathrm{~nm}$ ) were placed in front of camera lens to record only the heating radiation emitted in the $800-950 \mathrm{~nm}$ region. Beside these filters, neutral densities were also used to accommodate with low and high thermal radiation intensities. The camera axis was tilted $45^{\circ}$ with respect to rod axis. An imaging head with 2 achromatic lenses (with focal length of 65 and $120 \mathrm{~mm}$ ) also tilted $45^{\circ}$ with respect to rod axis, ensured the coupling between heat radiation emitted by a 0.6 $\mathrm{mm}$ diameter spot on the sample top surface and an optical fibre with $1 \mathrm{~mm}$ core diameter (and a numerical aperture of 0.2 ) connected to a spectrometer. The spectrometer (Ocean Optics USB2000+) operated in the wavelength range from 200 to $1100 \mathrm{~nm}$, with a recording rate up to $500 \mathrm{~Hz}$ and a spectral resolution of approximately $0.9 \mathrm{~nm}$. A He-Ne laser was used to carefully align the optics to the axis of the rod. The camera, the spectrometer, and the laser were triggered by the same signal, ensuring synchronous data acquisition. Time $t=0$ corresponds to the beginning of the laser pulse.

\section{CALIBRATION AND CALCULATION PROCEDURES}

\section{A. Theoretical background and data of emissivity from the literature}

Figure 2 shows the spectral luminance $L_{\lambda, B}$ of a black body, for some values of temperature, $T$, versus wavelength, $\lambda$, calculated using Planck's law (1),

$$
L_{\lambda, B}(\lambda, T)=\frac{2 h c^{2}}{\lambda^{5}} \frac{1}{\left(\exp \left(\frac{h c}{k_{b} \lambda T}\right)-1\right)},
$$

where $h$ is Planck's constant, $c$ is the speed of light, and $k_{b}$ is Boltzmann's constant.

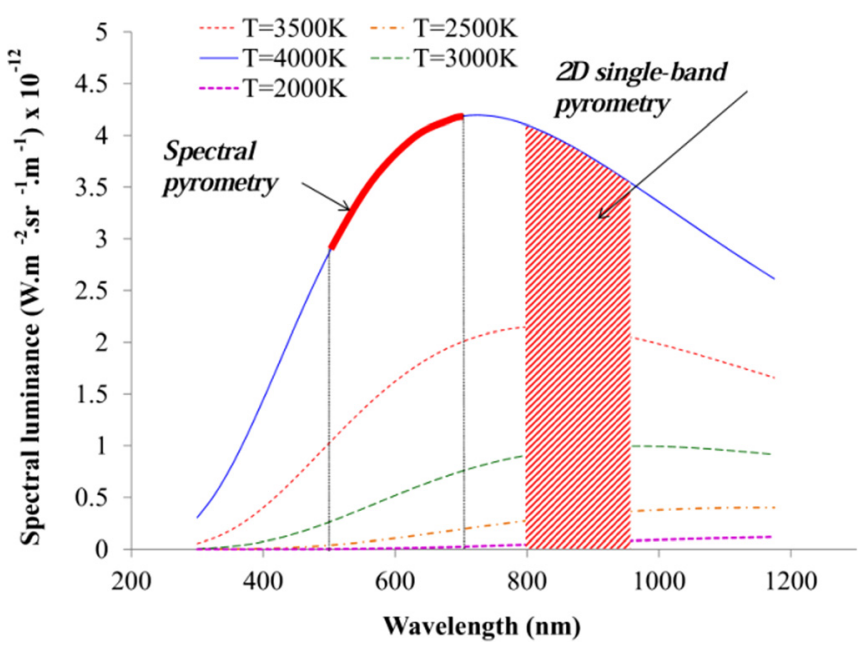

FIG. 2. Typical black body spectral luminance curves for various temperatures depending on wavelength. 
The ranges of wavelengths used in each technique are represented in Fig. 2: the spectrometer records spectra, i.e., spectral luminance of the sample surface from 500 to 700 $\mathrm{nm}$, while the high-speed video camera acquires the integrated luminance in the band $800-950 \mathrm{~nm}$, i.e., the spectral luminance integrated from 800 to $950 \mathrm{~nm}$.

For both techniques, the sensors were calibrated using the luminance of $\mathrm{V}, \mathrm{Nb}, \mathrm{Ta}$, and $\mathrm{W}$ at their melting point as a reference. The emissivity against the wavelength for $\mathrm{V}$, $\mathrm{Nb}, \mathrm{Ta}$, and $\mathrm{W}$, at their respective melting points (from the literature), are shown in Table I. In this work, the emissivity dependence on wavelength has been approximated by a linear function: $\varepsilon\left(\lambda, T_{\text {melt }}\right)=m \lambda+b$, where the parameters $m$ and $b$ for each species are reported in Table $\mathrm{I}$, where $T_{\text {melt }}$ is the melting temperature of each species, $\lambda_{\mathrm{x}}$ is the wavelength of the X-points (defined as the wavelength at which the spectral emissivity does not change with temperature, reported by Price in Ref. 15), $\varepsilon_{I R}\left(T_{\text {melt }}\right)$ is the averaged emissivity over the 800-950 $\mathrm{nm}$ region, calculated from data of the Table I and linearly extrapolated up to 950 and $1030 \mathrm{~nm}$.

\section{B. Spectral pyrometry}

The technique of spectral pyrometry used here takes into account the dependence of the emissivity on wavelength (assumed to be linear) and its variation through temperature changes. The temperature is deduced from the spectra acquired by the spectrometer using a suited algorithm that discriminates the part of the variations of the spectral luminance due to an emissivity variation with the wavelength from that due to a temperature change. Independent and simultaneous measurement of both temperature and emissivity are obtained but at a rate limited to $500 \mathrm{~Hz}$ and may give a good accuracy on the temperature, despite a poor knowledge of the emissivity of the sample or unexpected variations of emissivity.

The sensitivity of the spectrometer varies substantially in the 200-1100 $\mathrm{nm}$ range, as a result of the wide variation in sensitivity of the CCD sensors and the transmission factor of the optical components and the optical fibre. An appropriate calibration must thus be done.

For this purpose, the luminance of $\mathrm{V}, \mathrm{Nb}, \mathrm{Ta}$, and $\mathrm{W}$ at their melting point, are taken as references. A calibration factor $\eta(\lambda)$ defining the sensitivity of the spectrometer for each wavelength (in counts $\mathrm{W}^{-1} \mathrm{~m}^{2} \mathrm{sr} \mathrm{m}$ ) has been determined using emissivity data given in Table I,

$$
\eta(\lambda)=\frac{I\left(t_{\text {resol }}, \lambda\right)}{\varepsilon\left(\lambda, T_{\text {melt }}\right) \cdot L_{\lambda, B}\left(T_{\text {melt }}, \lambda\right)},
$$

where $I$ is the response of the spectrometer (in counts) at the time $t_{\text {resol }}$ during the resolidification plateau of temperature and $\varepsilon\left(\lambda, T_{\text {melt }}\right)$ is the emissivity at the melting point versus wavelength.

Figure 3 shows the evolution of $I, \eta$ and the theoretical spectral luminance of the surface of the rod at the melting point against wavelength. The profile of $\eta(\lambda)$ has a maximum at about $520 \mathrm{~nm}$, with a slower decrease for $\lambda>520 \mathrm{~nm}$. The range of measurement has been limited to $500-700 \mathrm{~nm}$ to avoid the strong rise between 400 and $500 \mathrm{~nm}$ and to ensure a level of $\eta$ of more than $15 \%$ of the peak on the whole range.

Then, the experimental spectral luminance $L_{\lambda, \exp }(\lambda)$ of a sample as a function of the wavelength can be easily obtained from the response $I$ of the spectrometer (in counts) using the following formula:

$$
L_{\lambda, \exp }(\lambda)=I(\lambda) / \eta(\lambda)
$$

This calibration procedure was carried out separately using the melting point of $\mathrm{V}, \mathrm{Nb}, \mathrm{Ta}$, or $\mathrm{W}$, with the appropriate emissivity (see Table I), and provided very similar results.

The ratio $L_{\lambda, \exp }(\lambda) /\left(L_{\lambda, B}\left(\lambda, T_{\text {melt }}\right) \cdot \varepsilon\left(\lambda, T_{\text {melt }}\right)\right)$ of the experimental luminance thus determined on the expected luminance has been calculated at the melting point of $\mathrm{V}, \mathrm{Nb}, \mathrm{Ta}$, and W. As shown in Fig. 4, this ratio varies very little on the whole wavelength range (less than $4 \%$ of variation for each plot) and the mean ratio of each curve is between 1.01 and 1.055. This shows that the emissivity data of the Table I are consistent and also demonstrates the linearity of the response of the sensors. Such small discrepancies can only have a very weak effect on the determination of the temperature as it will be shown below.

As mentioned above, the experimental spectra depend on the temperature and the emissivity of the sample. The dependence of the luminance on emissivity has been assumed to be linear, but its dependence on temperature is a nonlinear one. It is, therefore, possible to differentiate the variations of $L_{\lambda, \exp }(\lambda)$ due to temperature from those due to emissivity: when the emissivity increases, the curve is multiplied by a linear function of the wavelength, while an increase in temperature leads to a nonlinear increase of the amplitude with wavelength along with a shift of its maximum towards lower wavelengths. Let us define $L_{\text {calc }}(\lambda, m, b, T)$ as the product $(m \lambda+b) \cdot L_{\lambda, B}\left(\lambda, T_{\text {melt }}\right)$. To find the temperature corresponding to an experimental spectrum, one must thus determine the 3 parameters $m, b$, and $T$ for which $L_{\text {calc }}(\lambda, m, b, T)$ fits best the experimental luminance.

The fit was performed by using the Levenberg-Marquardt (L-M) nonlinear least squares algorithm, ${ }^{25}$ providing $m, b$,

TABLE I. Parameters $m$ and $b$ of $\varepsilon(\lambda)$ of $\mathrm{V}, \mathrm{Nb}, \mathrm{Ta}$, and $\mathrm{W}$ at their melting points, mean emissivity on the band 800-950 nm, temperature of fusion $T_{\text {melt }}$, and

\begin{tabular}{|c|c|c|c|c|c|c|}
\hline & $T_{\text {melt }}(\mathrm{K})$ & $\lambda_{\mathrm{x}}$ (Ref. 16) & $m \times 1 \times 10^{-4}\left(\mathrm{~nm}^{-1}\right)$ & $b$ & $\varepsilon_{I R}\left(T_{\text {melt }}\right)$ & $\varepsilon_{1030 \mathrm{~nm}}\left(T_{\text {melt }}\right)$ \\
\hline V & 2199 (Ref. 17) & 1430 & -0.681 (Ref. 18) & 0.387 (Ref. 18) & 0.32 & 0.306 \\
\hline $\mathrm{Nb}$ & 2749 (Ref. 19) & 850 & -1.76 (Ref. 20) & 0.456 (Ref. 20) & 0.31 & 0.289 \\
\hline $\mathrm{Ta}$ & 3270 (Ref. 21) & 840 & -1.72 (Ref. 22) & 0.492 (Ref. 22) & 0.35 & 0.325 \\
\hline W & 3695 (Ref. 23) & 1300 & -1.99 (Ref. 24) & 0.532 (Ref. 24) & 0.37 & 0.344 \\
\hline
\end{tabular}
wavelength $\lambda_{\mathrm{x}}$ of the X-points. 


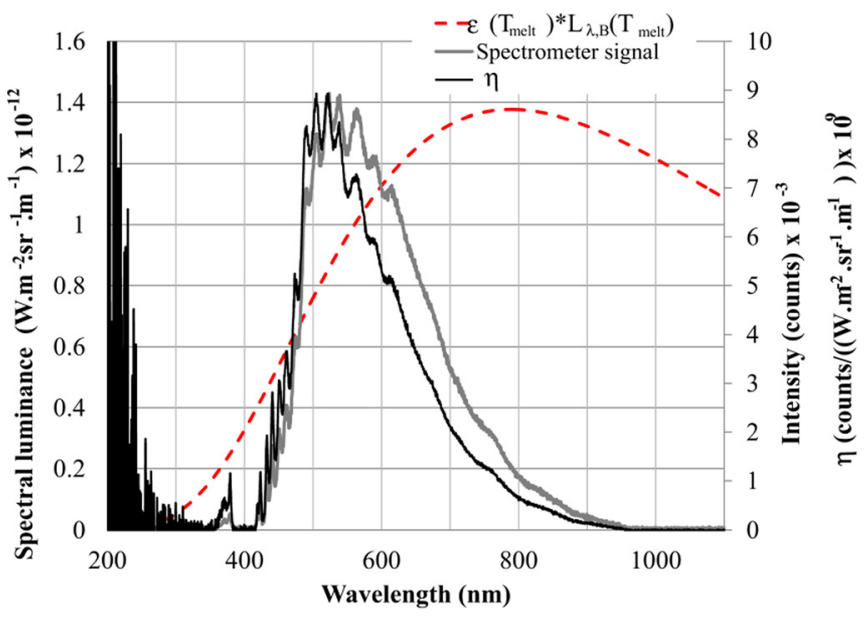

FIG. 3. Theoretical spectral luminance (dashed line) of a tungsten rod at the melting point, intensity measured by the spectrometer (gray plain line), and calibration factor $\eta$ (black plain line) as a function of the wavelength.

and $T$ values that give the smallest mean square error (MSE) between $L_{\lambda, \exp }(\lambda)$ and $L_{\text {calc }}(\lambda, m, b, T)$ defined as

$$
\operatorname{MSE}(m, b, T)=\sqrt{\frac{\sum_{i=1}^{N}\left(L_{\lambda, \exp }\left(\lambda_{i}\right)-L_{\text {calc }}\left(\lambda_{i}, m, b, T\right)\right)^{2}}{N}},
$$

where $\lambda_{i}$ are the wavelengths sampled by the spectrometer in the 500-700 $\mathrm{nm}$ range. The iterative process was interrupted when the relative difference between two consecutive MSEs was less than $10^{-8}$.

In order to quantify the quality of the fit, we define a $\beta$ coefficient that normalizes the MSE with the corresponding experimental luminance at $600 \mathrm{~nm}$, allowing thus the comparison of the quality for different experimental spectra,

$$
\beta(m, b, T)=\frac{M S E(m, b, T)}{L_{\lambda, \exp }(600 \mathrm{~nm})} .
$$

Moreover, spectra leading to $\beta$ coefficients greater than 0.1 were considered too noisy and, therefore, discarded.

The algorithm applied to the luminance of $\mathrm{V}, \mathrm{Nb}, \mathrm{Ta}$, and $\mathrm{W}$ at their melting points showed that for initial values $m, b$, and $T$ reasonably near from the expected values

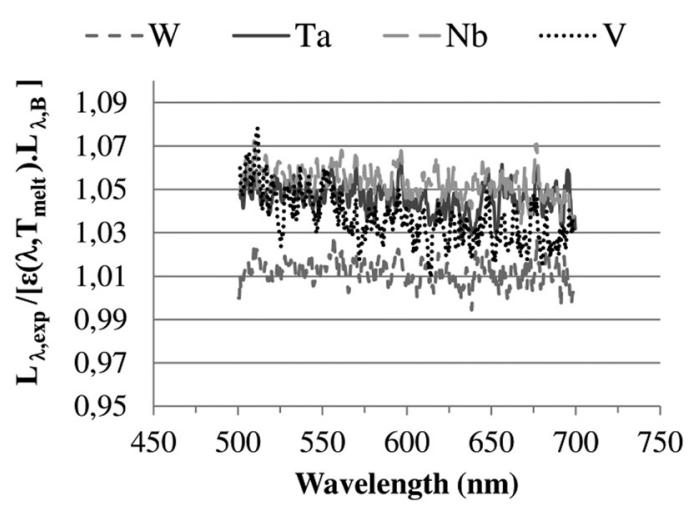

FIG. 4. Ratio of the experimental spectral luminance of $\mathrm{W}, \mathrm{Ta}, \mathrm{Nb}$, and $\mathrm{V}$ at their melting points to the expected luminance calculated from literature data of emissivity and Planck's law.
( $\pm 50 \%$ ), the best values $m, b$, and $T$ were successfully determined by the L-M algorithm, whatever combinations of initial $m, b$, and $T$ were chosen.

Extra cares were necessary in the case of totally unknown values of $m$ and $b$, as in the case of the combustion of pure iron in oxygen. To check the convergence of the L-M algorithm to the best solution and to be sure that a secondary minimum would not lead to erroneous results, in the case of initial values of $m, b$, and $T$ far from that of the best fit, $\beta$ was calculated for all the possible combinations of $m$, $b$, and $T$ in a wide selected range. Results show that, in the $(m, b, T)$-space, there is only one zone where $\beta$ is minimal. More precise results have been obtained by taking smaller and smaller ranges of $m, b$, and $T$ around the minimum of $\beta$.

Figure 5 shows the evolution of the minimal $\beta$ for different combinations of $T$ and $b$. Only is represented on the figure the minimal value of $\beta$ for each combination of $b$ and $T$, and the best corresponding $m$ is represented in color on the surface graph. This graph shows that, even for a quite large range of $b$ and $T, \beta$ has only one minimum.

\section{Uncertainty analysis}

Figure 6(a) shows the theoretical luminance of tungsten depending on the wavelength calculated from Eq. (1) (without noise) and the corresponding experimental luminance obtained from the spectrometer (with noise). The minimal $\beta$ coefficients as a function of the parameters $b$ and $T$ for the two cases (with and without noise) are represented as two surfaces in Fig. 6(b).

Figure 6(b) shows the evolution of the minimal $\beta$ calculated for different combinations of $b$ and $T$. It can be seen from the results that the spectra with and without noise lead to identical surfaces, except near the minimum of $\beta$. This minimum corresponds in both cases to the same combination of $b$ and $T$, but is much lower without noise (0.001) than with noise (0.02). These results show that the detector noise, close to a "white noise," is not really a source of uncertainty, because it does not change the determination of $m, b$, and $T$ corresponding to the minimum of $\beta$. The difference between the temperatures determined by the algorithm with and without noise is smaller than $1 \mathrm{~K}$.

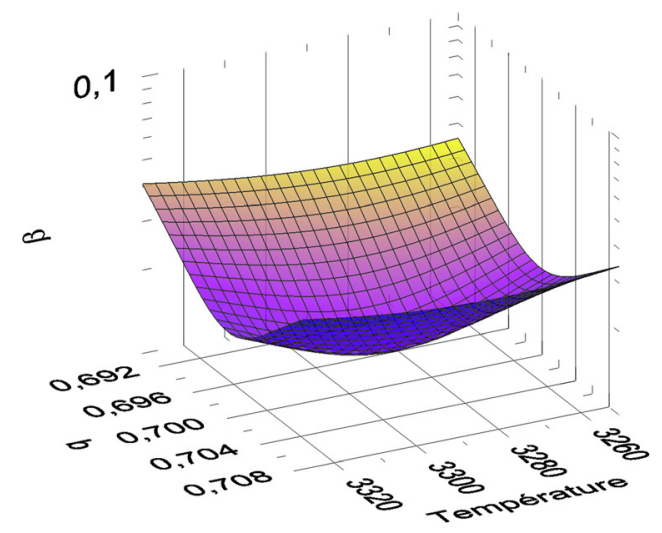

FIG. 5. Minimal $\beta$ depending on parameters $b$ and T. The colors represent the value of $m$ giving the smallest $\beta$ (dark: lower values of $m, m$ ranging from $-6.18 \times 10^{-4}$ to $13.6 \times 10^{-4}$ ). 


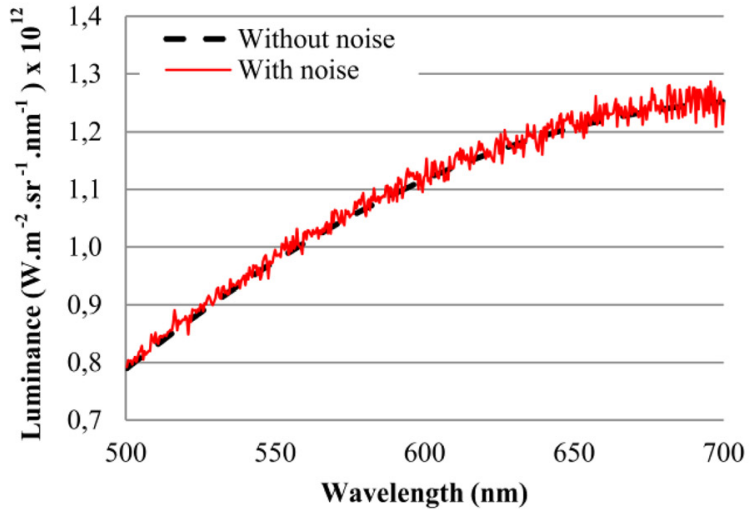

(a)

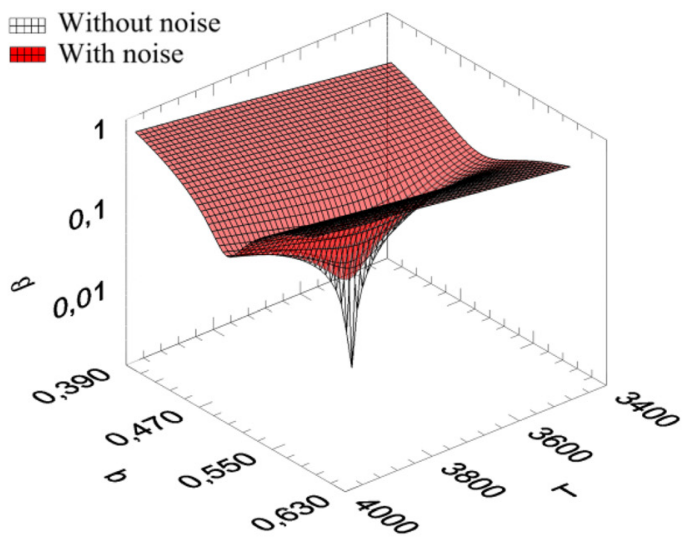

(b)

FIG. 6. (a) Spectra of $\mathrm{W}$ at the melting point with and without noise. (b) 3D graph of minimal $\beta$ depending on $b$ and $T$ in the case of theoretical and experimental spectrum of $\mathrm{W}$ at the melting point.

The main source of uncertainty lies in the calibration process. Indeed, calibration of the spectrometer was performed using the experimental spectrum of $\mathrm{W}$ at its melting point, which is given by the spectrum of a blackbody at $T_{\text {melt }}$ multiplied by the emissivity of tungsten $\varepsilon\left(\lambda, T_{\text {melt }}\right)=m_{\text {melt }}$. $\lambda+b_{\text {melt }}$ (see Table I). There are three sources of error: $\Delta m_{\text {melt }}, \Delta b_{\text {melt }}$, and $\Delta T_{\text {melt }}$, which are the uncertainties on the values of $m_{\text {melt }}, b_{\text {melt }}$, and $T_{\text {melt }}$, respectively, taken for the calculation of the spectral luminance of the blackbody at $T_{\text {melt }}$ and $\varepsilon\left(\lambda, T_{\text {melt }}\right)$.

The uncertainties on $m_{\text {melt }}, b_{\text {melt }}$, and $T_{\text {melt }}$ were found to be smaller than $20 \%, 10 \%$, and $10 \mathrm{~K}$ considering the data from different authors mentioned in Refs. 23 and 24. The effect of a possible error on $m_{\text {melt }}, b_{\text {melt }}$, and $T_{\text {melt }}$ for the calibration on each of the three parameters determined by the $\mathrm{L}-\mathrm{M}$ algorithm is reported in Table II. The two last columns give an upper bound of the relative uncertainties on $T, \varepsilon_{\text {mean }}$, $m$, and $b$, determined from two experimental spectra of tungsten at approximately 2400 and $3900 \mathrm{~K}$. These estimations were obtained by adding the relative uncertainties on each parameters $m_{\text {melt }}, b_{\text {melt }}$, and $T_{\text {melt }}$. It can be seen from these results that a variation in $b_{\text {melt }}$ or $m_{\text {melt }}$ used for the calibration leads to important variations of the values of $m$ and to a minor extent of those of $b$, but even after adding these uncertainties, the variations of the calculated temperature $T$ were always within a range of $3 \%$ (53 and $66 \mathrm{~K}$ at 2400 and 3900 $\mathrm{K}$, respectively).

The results of Table II also show that, considering the uncertainty in the value of $m_{\text {melt }}$ and $b_{\text {melt }}$ taken for the cali- bration, it would be inappropriate to try to accurately determine the absolute values of $m$ and $b$ from the experimental spectra. However, the mean value of the emissivity $\varepsilon_{\text {mean }}$ in the 500-700 nm range can be obtained by the formula $\varepsilon_{\text {mean }}=m \cdot 600 \mathrm{~nm}+b$ with an uncertainty of $25 \%-12 \%$ for a temperature ranging from 2400 to $3900 \mathrm{~K}$.

\section{2D single-band pyrometry}

For the 2D single-band pyrometry technique set up, a fast camera, equipped with an optical band-pass filter in the range from 800 to $950 \mathrm{~nm}$, was used. After calibration of the sensors, the camera provides 2D cartography of thermal radiation of the sample surface integrated in the band of wavelengths at frame rates up to $4 \mathrm{kHz}$. Calculations based on Planck's law allow the conversion of grey-level of each pixel to temperature, but this technique requires an a priori knowledge of the mean emissivity of the target within the appropriate wavelength range and the need to assume that it does not vary much with the temperature. This assumption is reasonable in the case of $\mathrm{V}, \mathrm{Nb}, \mathrm{Ta}$, and $\mathrm{W}$, because the considered spectral region is near the wavelength of the X-points (see in Table I).

In this case, the camera is sensitive to the integrated luminance of the sample on the $800-950 \mathrm{~nm}$ band (called "integrated luminance"). The theoretical integrated luminance $L_{B}(T)\left(\mathrm{W} \mathrm{m}^{-2} \mathrm{sr}^{-1}\right)$ of the black body on the 800-950 $\mathrm{nm}$ range is given by integration of Planck's law on the band $800-950 \mathrm{~nm}$,

TABLE II. Maximum deviations $\delta m, \delta b$, and $\delta T$ (in \%) of $m, b$, and $T$ resulting from variations $\Delta m_{\text {melt }} / m_{\text {melt }}, \Delta b_{\text {melt }} / b_{\text {melt }}$, and $\Delta T_{\text {melt }}$ of, respectively, $\pm 20 \%$, $\pm 10 \%$, and $\pm 10 \mathrm{~K}$ around the values taken from Refs. 23 and 24 .

\begin{tabular}{|c|c|c|c|c|c|c|c|c|}
\hline & \multicolumn{2}{|c|}{$\Delta m_{\text {melt }} / m( \pm 20 \%)$} & \multicolumn{2}{|c|}{$\Delta b_{\text {melt }} / b( \pm 10 \%)$} & \multicolumn{2}{|c|}{$\Delta T_{\text {melt }}( \pm 10 \mathrm{~K})$} & \multicolumn{2}{|c|}{ Total (\%) } \\
\hline & $2400 \mathrm{~K}$ & $3900 \mathrm{~K}$ & $2400 \mathrm{~K}$ & $3900 \mathrm{~K}$ & $2400 \mathrm{~K}$ & $3900 \mathrm{~K}$ & $2400 \mathrm{~K}$ & $3900 \mathrm{~K}$ \\
\hline$\delta T / T(\%)$ & 1.0 & 0.4 & 0.7 & 1.1 & 0.6 & 0.3 & 2.2 & 1.7 \\
\hline$\delta \varepsilon_{\text {mean }} / \varepsilon_{\text {mean }}$ & 9.6 & 2.4 & 10.5 & 9.1 & 5.3 & 0.2 & 25.3 & 11.8 \\
\hline$\delta m / m(\%)$ & 35.6 & 8.1 & 46.0 & 22.5 & 30.8 & 0.9 & 112.0 & 31.6 \\
\hline$\Delta b / b(\%)$ & 11.9 & 0.5 & 5.7 & 3.8 & 9.3 & 0.4 & 26.8 & 4.7 \\
\hline
\end{tabular}




$$
L_{B}(T)=\int_{800 \mathrm{~nm}}^{950 \mathrm{~nm}} L_{\lambda, B}(\lambda, T) d \lambda .
$$

The previous expression can be simplified by observing that the following expression is very well verified on the 2000-5000 K temperature range:

$$
L_{B}(T)=\int_{800 \mathrm{~nm}}^{950 \mathrm{~nm}} L_{\lambda, B}(\lambda) \cdot d \lambda=c_{0} \cdot L_{875 \mathrm{~nm}, B} .
$$

Moreover, the integrated luminance $L_{R}$ of the real sample is given by the formula

$$
L_{R}(T)=\varepsilon_{I R}(T) \cdot L_{B}(T),
$$

where $\varepsilon_{I R}$ is the mean emissivity on the $800-950 \mathrm{~nm}$ band.

The variable $X$ is defined by

$$
X=L_{R}(T) \cdot \tau \cdot 10^{-D}
$$

where $\tau$ is the integrating time of the camera (s) and $D$ is the logarithmic coefficient of the neutral density placed in front of the camera.

The linearity of the response of the sensors of the highspeed camera was verified by monitoring the brightness of a diffusing target (with $\mathrm{BaSO}_{4}$ coating) illuminated with linearly increasing laser pulses. One can thus deduce that there exists a relation between $N_{g}$ and $X$ such that

$$
N_{g}=k \cdot X+d,
$$

where $N_{g}$ is the grey-level (on 8 bits), $k$ is an optical efficiency factor, and $d$ is a constant.

For each metal, the top of the rod is monitored using the camera in the 800-950 $\mathrm{nm}$ range during laser heating and the cooling that follows. The parameters of irradiation (power and pulse duration) were chosen such that the top of the rod was totally melted, but the thickness of the melt being very small to keep a flat surface.

Figure 7 shows $N_{g}$ versus $X$ obtained from the luminance of the melting point of the different metals, for different combinations of $\tau$ and $D$. This was done in order to get points evenly spread in the whole range of the sensor. The absolute uncertainty on the determination of $N_{g}$ is estimated

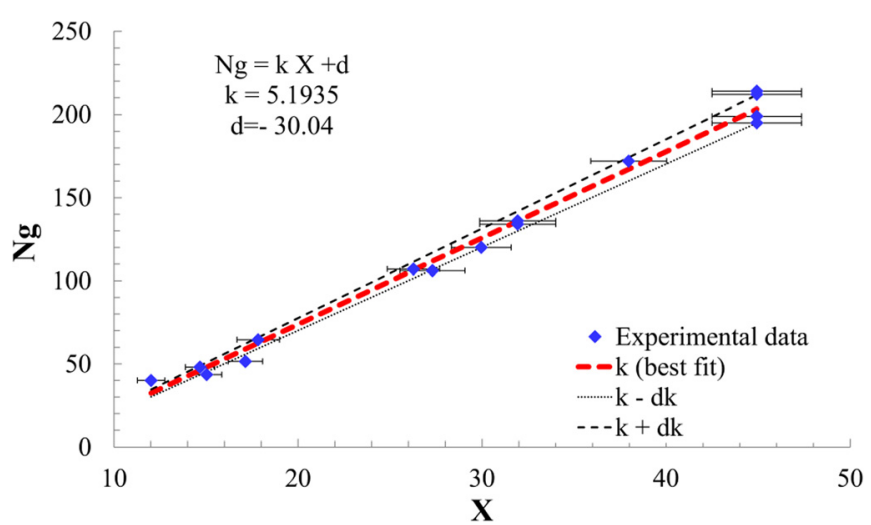

FIG. 7. Scattered plot of the grey-level depending on $\mathrm{X}$ for the different melting points and various parameters of the camera $(\tau$ and $D)$ and best fit by the least square method. to be equal to \pm 2 , and the relative uncertainty on mean emissivity $d \varepsilon / \varepsilon$ at the melting point taken from Refs. 18, 20, 22, and 24 was equal to \pm 0.02 .

Figure 8(a) shows typical pictures obtained with the fast video camera in the case of the heating and cooling of a tungsten rod. A small discontinuity in the emissivity at the phase change induces a slight change in the brightness of the rod, indicating when the centre of the rod starts to melt, as well as when it solidifies. During the resolidification, a plateau in the temperature due to the latent heat of fusion is seen. It was more difficult to detect during the melting because of the simultaneous laser heating. Consequently, it is the resolidification plateau that was used for the determination of luminance reference, at the melting point for each metal.

The slope $k=5.1935$ and the intercept $d=-30.04$ of the best fitting line were determined using the method of the least squares while accounting for the uncertainty on $X$ and $N_{g}{ }^{26}$ The negative value of $d$ means that the sensors have an illumination threshold below which no light is detected.

A relation between $T$ and the luminance of the black body at the same temperature than that of the real sample $L_{B}$ is obtained from the combination of Eqs. (1) and (7),

$$
L_{B}(T)=C_{1}\left(\exp \left(C_{2} / T\right)-1\right)^{-1},
$$

with $C_{1}=2 c_{0} h c^{2} \lambda_{0}^{-5}, C_{2}=h c /\left(k_{b} \lambda_{0}\right)$, and $\lambda_{0}=875 \mathrm{~nm}$.

The combination of Eqs. (8)-(10) leads to the following formula for $L_{B}$ :

$$
L_{B}=\left(N_{g}-d\right) /\left(k \varepsilon_{I R} \tau 10^{-D}\right) .
$$

One can then obtain $T$ from the experimental parameters by combining Eqs. (11) and (12),

$$
T=C_{2} \cdot \ln ^{-1}\left(\frac{C_{1} k \varepsilon_{I R} \tau 10^{-D}}{N_{g}-d}+1\right) .
$$

\section{Uncertainty analysis}

There are three sources of uncertainty in the temperature: from $k, \varepsilon_{\mathrm{IR}}$, and $N_{g}$. The relative uncertainty $d k / k$ is calculated ${ }^{26}$ to be equal to $0.036 ; d N_{g}$ was taken to be equal to 2 and $d \varepsilon_{\mathrm{IR}} / \varepsilon_{\mathrm{IR}}$ to 0.05 in the case of $\mathrm{W}, \mathrm{Ta}, \mathrm{Nb}, \mathrm{V}$, and metal combustion, in order to take into account possible variations of $\varepsilon_{\mathrm{IR}}$ with the temperature.

Considering the linear relation between $L_{B}, N_{g}, \varepsilon_{\mathrm{IR}}$, and $k$, the final relative uncertainty on the luminance of the black body at the same temperature than that of the real sample is given by

$$
\left|d L_{B} / L_{B}\right|=\left|d N_{g} /\left(N_{g}-d\right)\right|+\left|d k^{\prime} / k^{\prime}\right|+\left|d \varepsilon_{I R} / \varepsilon_{I R}\right| .
$$

Equation (11) being monotonic, one can simply infer the uncertainty (2.dT) in $T$ using the equation

$$
2 \cdot d T=\left|T\left(L_{B}+d L_{B}\right)-T\left(L_{B}-d L_{B}\right)\right| .
$$

For the tungsten rods at $3700 \mathrm{~K}$ and niobium rods at $2600 \mathrm{~K}$, $d T$ was found to be of 75 and $60 \mathrm{~K}$, respectively. 


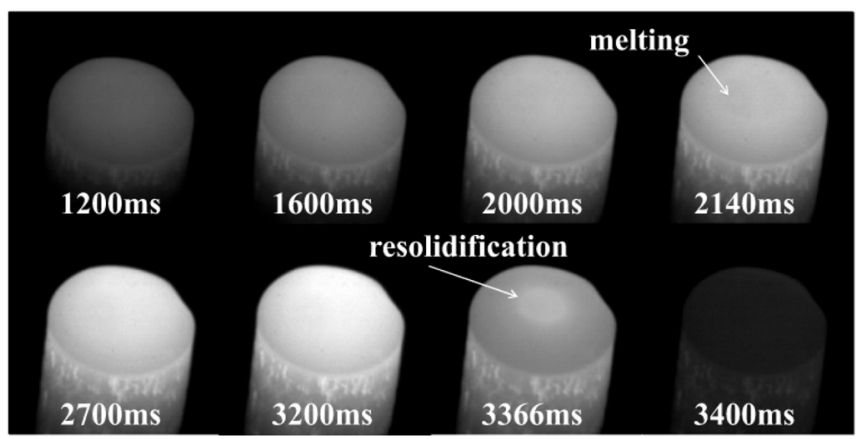

(a)

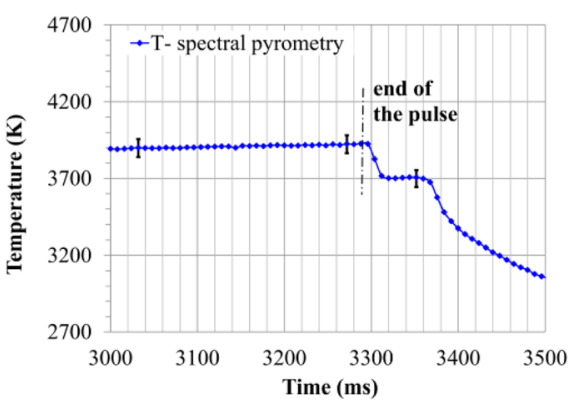

(b)

FIG. 8. (a) Temporal evolution of thermal radiation of laser heated tungsten rod (1 kW-3.3 s) observed with the fast video camera. (b) Temperature evolution around solidification determined with the spectral pyrometry technique.

\section{RESULTS}

\section{A. Temperatures of $\mathrm{V}, \mathrm{Nb}, \mathrm{Ta}, \mathrm{W}$ during laser heating cycles}

Figure 8(a) shows the pictures of a tungsten rod during the laser heating and the cooling process. A slight discontinuity can be detected during the melting and the resolidification of the rod. Figure 8(b) shows the temperature evolution with the characteristic plateau of solidification during the cooling.

Figures 9(a) and 9(b) show the temporal evolution of the temperature during the heating and cooling cycle of a tungsten rod and a niobium rod. The shaded zones correspond to the zone of discarded measures of the spectrometer, that is, when $\beta$ greater than 0.1 . The temperatures determined by both methods are very similar and the difference $\Delta T$ between them does not exceed $100 \mathrm{~K}$ at approximately $3920 \mathrm{~K}$, and $60 \mathrm{~K}$ at $2600 \mathrm{~K}$ (a difference of less than $3 \%$ ).

\section{B. Temperatures and mean emissivity of iron and steel during combustion process}

In the case of combustion, the emissivity may vary from one measurement to another, and the surface has not a homo- geneous temperature anymore as in the case of laser heating under argon.

Both techniques of temperature measurement described above were applied to the combustion process of a CS S355 $(0.2 \%$ of C) and a pure iron (more than $99.99 \% \mathrm{Fe}$ ) rod. The emissivity of the observed zone taken in the case of $2 \mathrm{D}$ single-band pyrometry was 0.7 .

Figures 10(a) and 10(b) show images from the combustion process of a CS and a pure iron rod in an oxygen atmosphere (at ambient pressure) ignited by laser. The heating leads to the melting of the surface of the rod. As soon as the liquid is formed on the top, the temperature increases very sharply, due to the combustion process that takes place in the melt. Then, at $t=100 \mathrm{~ms}$, a violent ebullition of the metal and oxide melt in the case of the CS rod is observed, whereas in the case of iron no ebullition is noticed.

In the steelmaking process metallurgy, melted iron $\mathrm{FeO}$ is known to react with carbon in a bath containing melted steel, leading to the formation of $\mathrm{CO}$ and $\mathrm{CO}_{2}$. This phenomenon, called decarburization, is suspected to be responsible for the violent ebullition of the iron and iron oxide melt during the combustion process of $\mathrm{CS}^{27}$

The temporal evolution of temperature of the centre of top of the rod determined by both techniques and emissivity

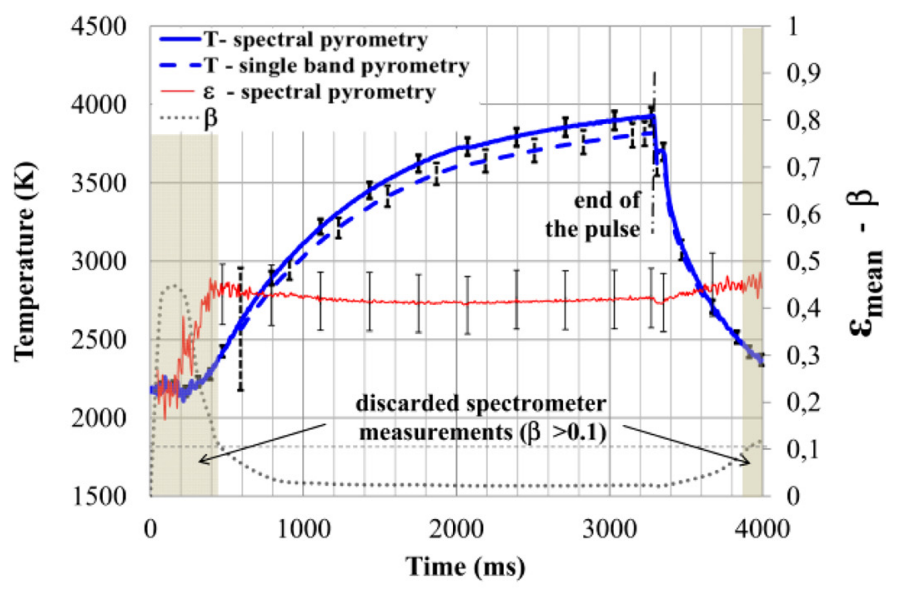

(a)

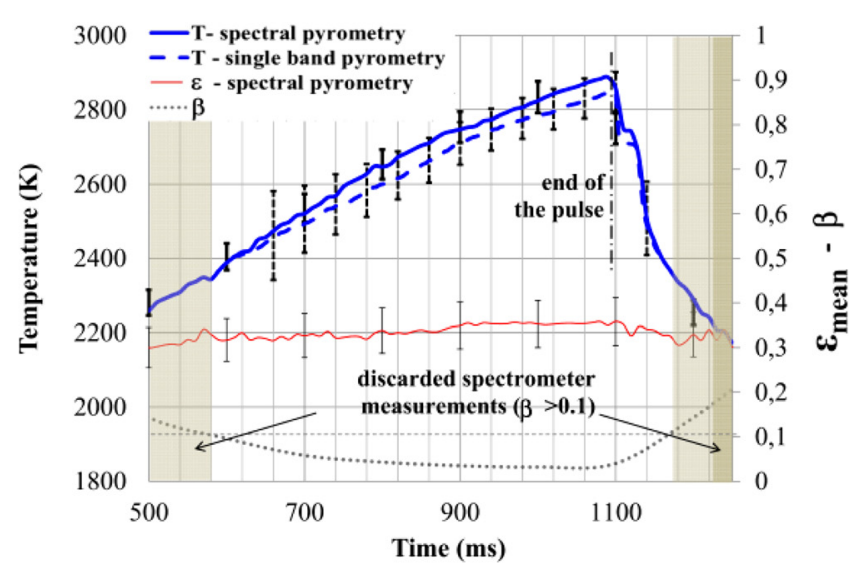

(b)

FIG. 9. Temporal evolution of the temperature through laser heating and cooling, determined by both techniques, and evaluation of the mean emissivity $\varepsilon$ by the polychromatic technique (a) for $\mathrm{W}(1 \mathrm{~kW}-3.3 \mathrm{~s})$ and (b) for $\mathrm{Nb}(1 \mathrm{~kW}-1.1 \mathrm{~s})$. 
(a)

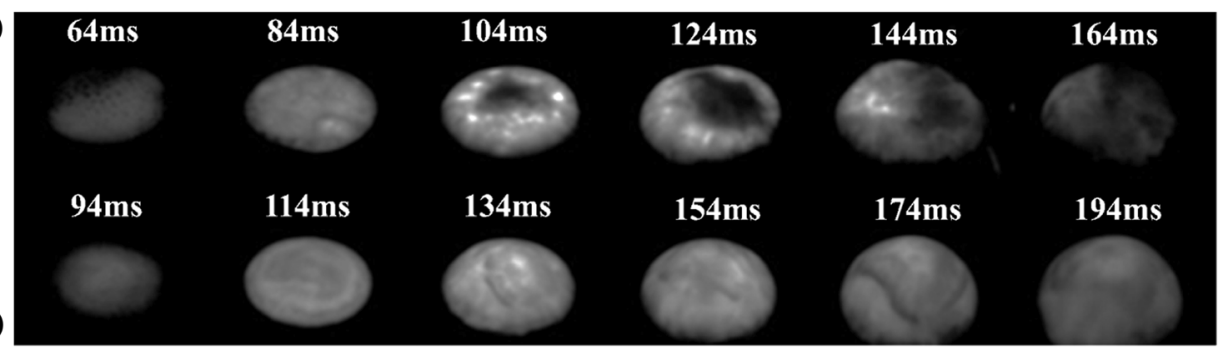

FIG. 10. Combustion of a rod under oxygen atmosphere: (a) carbon steel and (b) pure iron.

through the combustion process are represented in Fig. 11. The graphs can be divided in 3 main regions. In region I, temperature is increasing up to approximately $3100 \mathrm{~K}$ for both rods, with a roughly constant emissivity of 0.7 . In the region II, temperature reaches a plateau for a pure iron rod with unchanged brightness of the sample, but decreases slightly for CS along with a strong decrease of the mean emissivity. For iron, the two techniques give the same results in the region II and the mean emissivity measured with spectral pyrometry remains quite constant. On the other hand, in the case of CS combustion, a strong discrepancy between the temperatures obtained by spectral or single-band pyrometry is observed, coinciding with the apparition of a "black area."
After the end of the laser pulse (region III), the surface temperature decreases in both cases and the emissivity remains stable at $0.65-0.7$ for both samples.

This black area visible on the film of CS combustion from $t=100$ to $t=160 \mathrm{~ms}$ may be due to a decrease of the emissivity or a decrease of the temperature of this zone. Yet, the emissivity determined by spectral pyrometry shows a strong decrease when this black area appears, along with a smaller decrease of the temperature. Indeed, the bubbles of $\mathrm{CO}$ formed by decarburization explode violently, exposing at the surface less oxidized iron, whose emissivity (around 0.45 ) is closer to that of melted nonoxidized iron: 0.39 [at $1890 \mathrm{~K}$ (Ref. 28)], in which temperature is smaller
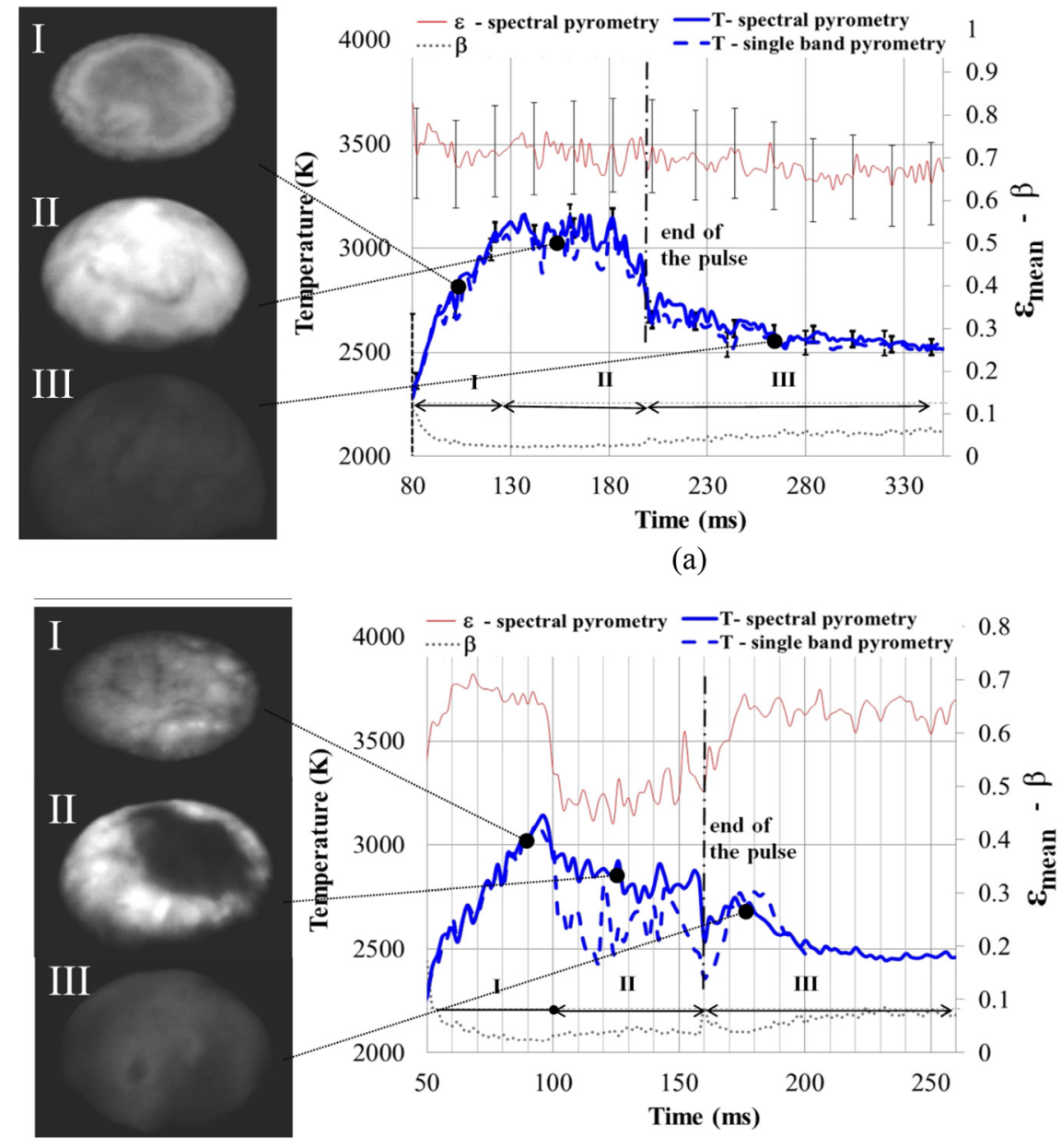

(b)

FIG. 11. Temporal evolution of the temperature through combustion by both optical pyrometry techniques and evaluation of the mean emissivity $\varepsilon_{\text {mean }}$ by the polychromatic technique (a) of a pure iron rod (laser: $0.64 \mathrm{~kW}-0.19 \mathrm{~s}$ ) (b) of a carbon steel rod (laser: $0.64 \mathrm{~kW}-0.16 \mathrm{~s}$ ). 
than that of the surface exposed to laser heating. The $\beta$ coefficient remains low between $t=100$ and $t=160 \mathrm{~ms}$, even during this variation of emissivity, supporting the fact that the experimental spectra are well fitted by the L-M algorithm and that the smaller emissivity detected by the spectral pyrometry technique is not a by-product of the algorithm.

Predictably, the single-band pyrometry technique gives erroneous measurements during the apparition of the black area, because it does not take into account the change of emissivity of the observed zone and, thus, considers a decrease of the brightness as a decrease of the temperature.

In this particular configuration, spectral pyrometry technique proves able to detect and even roughly quantify a strong variation of the emissivity occurring during the combustion process, and takes into account this variation to give a correct evaluation of the temperature.

\section{COMPARISON OF THE RESULTS WITH A COMSOL SIMULATION}

\section{A. Description of the model}

A COMsol Multiphysics model with only heat transfer module of the heating of a rod by laser and under argon has been made.

In order to check the validity of the model, absorptivity and temperature measurements of $\mathrm{V}, \mathrm{Ta}, \mathrm{Nb}$, and $\mathrm{W}$ rods have been performed and compared to simulations.

As showed in Fig. 12, the rod is represented as a rectangle of $(D / 2) \times 250 \mathrm{~mm}$ in size, where $D$ is the diameter of the rod delimited by the axis of symmetry on one vertical side, and insulated walls elsewhere.

The transient temperature distribution $T(r, z, t)$ is obtained from the resolution of the heat conduction equation in the rod,

$$
\rho \cdot c_{p_{-} e f f} \frac{\partial T}{\partial t}=\vec{\nabla} \cdot\left(k_{t h} \cdot \vec{\nabla} T\right)
$$

where $k_{\mathrm{th}}$ is thermal conductivity ( $\mathrm{W} \mathrm{m}{ }^{-1} \mathrm{~K}^{-1}$ ), $\rho$ is density $\left(\mathrm{kg} \mathrm{m}^{-3}\right), t$ is time (s), $T$ is temperature $(\mathrm{K})$, and $c_{p_{-} \text {eff }}$ is the effective specific heat capacity $\left(\mathrm{J} \mathrm{kg}^{-1} \mathrm{~K}^{-1}\right)$, where the latent heat of fusion $L_{f}\left(\mathrm{~J} \mathrm{~kg}^{-1}\right.$ ) (see Table III) is taken into account as an increase of the specific heat capacity value around the temperature of fusion. Thus, this effective specific heat capacity can be described by the following equation:

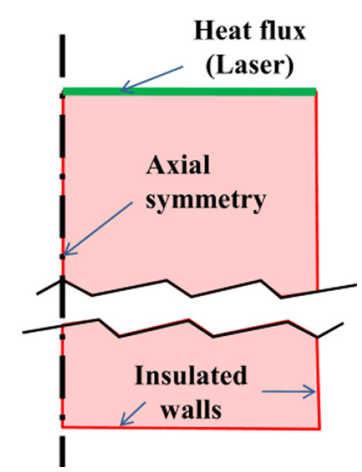

FIG. 12. Description of the boundary conditions of the COMSOL model.
TABLE III. References of the thermophysical properties used in the simulation.

\begin{tabular}{lcccc}
\hline \hline & $c_{p}\left(\mathrm{~J} \mathrm{~kg}^{-1} \mathrm{~K}^{-1}\right)$ & $k_{\mathrm{th}}\left(\mathrm{W} \mathrm{m}^{-1} \mathrm{~K}^{-1}\right)$ & $\rho\left(\mathrm{kg} \mathrm{m}^{3}\right)$ & $L_{f}\left(\mathrm{~kJ} \mathrm{~kg}^{-1}\right)$ \\
\hline $\mathrm{V}$ & Ref. 29 & Ref. 30 & Refs. 31-33 & 410 (Ref. 34) \\
$\mathrm{Nb}$ & Ref. 30 & Ref. 30 & Refs. 32, 35, and 37 & 285 (Ref. 36) \\
$\mathrm{Ta}$ & Ref. 29 & Ref. 30 & Refs. 38 and 39 & 172 (Ref. 40) \\
$\mathrm{W}$ & Refs. 19 and 41 & Ref. 30 & Refs. 39, 42, and 43 & 193 (Ref. 44) \\
\hline \hline
\end{tabular}

$$
\begin{aligned}
c_{p_{-} \mathrm{eff}}(T) & =L_{f} \cdot D_{\exp }(T)+c_{p}(T), \text { with } \\
D(T) & \left.=\exp -\left(\frac{T-T_{\text {melt }}}{\Delta T_{0}}\right)^{2}\right) /\left(\Delta T_{0} \cdot \sqrt{\pi}\right),
\end{aligned}
$$

where $\Delta T_{0}$ is the temperature interval on which the effect of latent heat exchange is numerically introduced (typically $\Delta T_{0}$ of about $100 \mathrm{~K}$ was used for the present simulations) and $c_{p}$ is the specific heat capacity of the metal.

A heat source $q_{0}\left(\mathrm{~W} \mathrm{~m}^{-2}\right)$ with homogeneous intensity stands for the laser irradiating the top of the rod,

$$
q_{0}=A \cdot P / S,
$$

where $A$ is the absorptivity coefficient of the sample, $P$ the power of the laser (W), and $S$ the surface of the top of the $\operatorname{rod}\left(\mathrm{m}^{2}\right)$. The absorptivity $A$ of the sample at $1030 \mathrm{~nm}$ has been taken equal to its emissivity at $1030 \mathrm{~nm}$ (Table I), using Kirchhoff's law, and considered to be constant through the heating process to that of its melting point.

The validity of this model is limited to solid phase configuration, but given the geometry of the rod, approaching a one-dimensional configuration, it has been extended to the beginning of the melting of the top of the rod: as the melted layer thickness is not exceeding approximately $1 \mathrm{~mm}$, convective flows in the melt due to Marangoni effect are avoided.

The thermophysical properties of $\mathrm{V}, \mathrm{Nb}, \mathrm{Ta}$, and $\mathrm{W}$ depending on temperature have been taken from various articles. The references are reported in Table III.

Thermal losses and the laser heating at the walls are taken into account by introducing the following boundaries conditions:

$$
\begin{aligned}
-\vec{n} \cdot\left(-k_{t h} \overrightarrow{\nabla T}\right)= & h_{\text {conv }}\left(T_{\mathrm{inf}}-T\right) \\
& \text { for the side and bottom walls, } \\
-\vec{n} \cdot\left(-k_{t h} \overrightarrow{\nabla T}\right)= & q_{0}+h_{\text {conv }}\left(T_{\mathrm{inf}}-T\right) \\
& \quad \text { for the upper wall, }
\end{aligned}
$$

where $\vec{n}$ is unity vector normal to the surface, $h_{\text {conv }}$ is the heat convection coefficient, and $T_{\text {inf }}$ is the temperature outside the rod. In our model, $h_{\text {conv }}$ has been taken to be equal to 100 .

\section{B. Results}

The results of the computations are presented in Fig. 13, along with the experimental data obtained with our spectral 


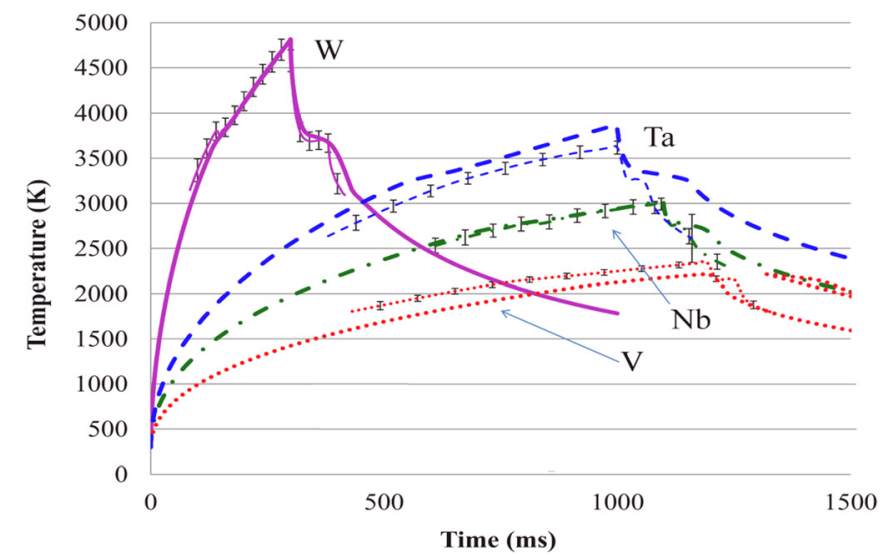

FIG. 13. Experimental temporal evolution of the temperature from the spectral pyrometry measurements, and corresponding calculations using COMSOL simulation, for the following laser irradiations: W: $3 \mathrm{~kW}-0.3 \mathrm{~s}$, Ta: 1 kW-1.2 s, Nb: $1 \mathrm{~kW}-1.1 \mathrm{~s}, \mathrm{~V}: 640 \mathrm{~W}-1.2 \mathrm{~s}$.

pyrometry device. These results show good agreement between measurements and calculations. The cooling temperature plateau is not perfectly reproduced by the simulation, but the thermal losses were very roughly determined in the model, and possible source of losses might have been neglected.

\section{CONCLUSION}

This work allowed to setup and to validate two independent and complementary temperature measurement techniques both based on optical pyrometry, particularly adapted to high temperatures, in a wide range of values, spatially and time-resolved and usable in harsh conditions. The use of these techniques would be particularly valuable in all laserprocessing techniques, whenever unexpected changes of the emissivity, being due to oxidation or even to a possible change in the geometry of the observed zone (welding, metal deposition laser process, cutting, etc.) could occur.

The calibrations processes, based on the use of the luminance of pure materials at their melting point, and the calculation procedure were explained. The relevance of the calibration technique has been shown, and an analysis of the uncertainty has been done. A comparison between the measurements obtained by the two techniques has been made, for different species and ranges of temperature, and a good agreement was found. Both techniques give temperature measurement with accuracy from approximately $\pm 3 \%$ (spectral pyrometry) to $\pm 5 \%$ (single-band pyrometry) depending on the range of temperature. The results of each technique are always in the uncertainty bars of that of the other.

The 2D single-band pyrometry technique provides a control of the geometry of the sample and allows high rate of measurement, valuable in the case of very quick changes in the temperature. The integrated luminance of the sample in a $150 \mathrm{~nm}$-wide band of wavelength and a good sensitivity of the camera offer the possibility to choose a small averaging time and thus to obtain very good temporal resolution of the measurements. The use of a fixed range of wavelengths offers the advantage of avoiding concerns about dependence of $\varepsilon$ from $\lambda$. This technique requires, however, a previous good knowledge of the emissivity in this range and is inappropriate in the case of abrupt changes in emissivity.

In the spectral pyrometry technique, the emissivity depending on the wavelength is unknown, but assumed to be linear. This allowed, using the L-M algorithm, on one hand to determine precisely the temperature and on the second hand to give a good evaluation of the relative mean emissivity of the sample on the range of 500-700 nm. Results showed that unexpected emissivity of the sample or abrupt variations of the emissivity would not impair the measurement of the temperature, contrarily to the single-band pyrometry technique.

The validation of a 2D axis-symmetrical comsol model with heat transfer module and thermophysical data for each species taken from the literature has been obtained by comparison with temperature measurements made at the surface of $\mathrm{V}, \mathrm{Nb}, \mathrm{Ta}$, and $\mathrm{W}$ rods under argon. The calculated surface temperatures are very close to the corresponding measurements. Such model could be used as well in the case of a surface during its oxidation, by modifying the absorptivity of the surface through the process, or in the case of combustion, by adding an extra volumic heat source corresponding to release inside the melt due to oxidation.

\section{ACKNOWLEDGMENT}

This work was supported by Air Liquide CRCD Company and has been realized on the site of Arts et Métiers ParisTech in Paris.

${ }^{1}$ H. G. Kraus, "Optical spectral radiometric method for measurement of weld-pool surface temperatures," Opt. Lett. 11(12), 773-775 (1986).

${ }^{2}$ B. Carcel, J. Sampedro, I. Perez, E. Fernandez, and J. A. Ramos, "Improved laser metal deposition (lmd) of nickel base superalloys by pyrometry process control," in Proceedings of the XVIII International Symposium on Gas Flow, Chemical Lasers, and High-power Lasers (Bellingham, Washington, 2010), p. 7751.

${ }^{3}$ V. Onuseit, M. A. Ahmed, R. Weber, and T. Graf, "Space-resolved spectrometric measurements of the cutting front," Phys. Procedia 12, 584-590 (2011).

${ }^{4}$ A. N. Magunov, "Spectral pyrometry (review)," Instrum. Exp. Tech. 52(4), 451-472 (2009).

${ }^{5}$ W. C. Reynolds, "Investigation of ignition temperature of solid metals," NASA Technical note (Report number NASA-TN-D-182) (freely available on the NASA Technical Reports Server), 1959.

${ }^{6}$ K. Nguyen and M. C. Branch, "Near-infrared 2-color pyrometer for determining ignition temperatures of metals and metal-alloys," Rev. Sci. Instrum. 56(9), 1780-1783 (1985).

${ }^{7}$ J. W. Bransford, "Ignition and combustion temperatures determined by laser heating," in Flammability and Sensitivity of Materials in OxygenEnriched Atmospheres (American Society for Testing and Materials, West Conshohocken, PA, 1986), Vol. 2, pp. 78-97.

${ }^{8}$ J. Kurtz, T. Vulcan, and T. A. Steinberg, "Emission spectra of burning iron in high-pressure oxygen," Combust. Flame 104(4), 391-400 (1996).

${ }^{9}$ L. S. Nelson, J. M. Bradley, J. H. Kleinlegtenbelt, P. W. Brooksans, and M. L. Corradini, Studies of Metal Combustion (Fusion Technology Institute, Wisconsin, 2003).

${ }^{10} \mathrm{R}$. Bouriannes and M. Moreau, "Un pyromètre rapide à plusieurs couleurs," Rev. Phys. Appl. 12, 893-899 (1977).

${ }^{11}$ J. L. Gardner, "Effective wavelength for multicolor-pyrometry," Appl. Opt. 19(18), 3088-3091 (1980).

${ }^{12}$ G. B. Hunter, C. D. Allemand, and T. W. Eagar, "Prototype device for multiwavelength pyrometry," Opt. Eng. 25(11), 1222-1231 (1986).

${ }^{13}$ X. G. Sun, G. B. Yuan, J. M. Dai, and Z. X. Chu, "Processing method of multi-wavelength pyrometer data for continuous temperature measurements," Int. J. Thermophys. 26(4), 1255-1261 (2005). 
${ }^{14}$ J. Weberpals, R. Schuster, P. Berger, and T. Graf, "Utilization of quantitative measurement categories for process monitoring," in Proceedings of the 29th International Congress on Applications of Lasers and ElectroOptics (Laser Institute of America, Anaheim, CA, 2010), pp. 44-52.

${ }^{15}$ D. J. Price, "The temperature variation of the emissivity of metals in the near infra-red," Proc. Phys. Soc., London, Sect. A 59(331), 131-138 (1947).

${ }^{16}$ C. Ronchi, J. P. Hiernaut, and G. J. Hyland, "Emissivity X-points in solid and liquid refractory transition metals," Metrologia 29, 261-271 (1992).

${ }^{17}$ G. Pottlacher, T. Hüpf, B. Wilthan, and C. Cagran, "Thermophysical data of liquid vanadium," Thermochim. Acta 461(1-2), 88-95 (2007).

${ }^{18}$ J. L. McClure and A. Cezairliyan, "Radiance temperatures (in the wavelength range 525 to $906 \mathrm{~nm}$ ) of vanadium at its melting point by a pulseheating technique," Int. J. Thermophys. 18(1), 291-302 (1997).

${ }^{19}$ A. Cezairliyan, "High-speed (subsecond) measurement of heat-capacity, electrical resistivity, and thermal-radiation properties of niobium in range 1500 to 2700 K," J. Res. Natl. Bur. Stand., Sect. A 75(6), 565-570 (1971).

${ }^{20}$ A. Cezairliyan and A. P. Miiller, "Radiance temperatures (in the wavelength range 522-906 nm) of niobium at its melting-point by a pulseheating technique," in Proceedings of the 2nd Workshop on Subsecond Thermophysics (CNR, Ist Metrol Gustavo Colonnetti, Torino, Italy, 1992), Vol. 13(1), pp. 39-55.

${ }^{21}$ H. Jager, W. Neff, and G. Pottlacher, "Improved thermophysical measurements on solid and liquid tantalum," Int. J. Thermophys. 13(1), 83-93 (1992).

${ }^{22}$ A. Cezairliyan, J. L. Mcclure, and A. P. Miiller, "Radiance temperatures (in the wavelength range $520-906 \mathrm{~nm}$ ) of tantalum at its melting point by a pulse-heating technique," High Temp.-High Press. 25(6), 649-656 (1993).

${ }^{23}$ A. Cezairliyan, "Measurement of melting-point and electrical resistivity (above $3600 \mathrm{~K}$ ) of tungsten by a pulse heating method," High Temp. Sci. 4(3), 248-252 (1972).

${ }^{24}$ A. P. Miiller and A. Cezairliyan, "Radiance temperatures (in the wavelength range 519-906 $\mathrm{nm}$ ) of tungsten at its melting-point by a pulseheating technique," Int. J. Thermophys. 14(3), 511-524 (1993).

${ }^{25} \mathrm{P}$. Bevington and K. Robinson, Data Reduction and Error Analysis for the Physical Sciences (McGraw-Hill, Boston, MA, 2003), pp. 161-165.

${ }^{26}$ D. York, N. M. Evensen, M. L. Martinez, and J. D. Delgado, "Unified equations for the slope, intercept, and standard errors of the best straight line," Am. J. Phys. 72(3), 367-375 (2004).

${ }^{27}$ M. D. Lanyi, "Discussion on steel burning in oxygen (from a steelmaking metallurgist's perspective)," in Flammability and Sensitivity of Materials in Oxygen-Enriched Atmospheres (American Society for Testing and Materials, West Conshohocken, PA, 2000), Vol. 9, pp. 163-178.

${ }^{28}$ S. Krishnan, K. J. Yugawa, and P. C. Nordine, "Optical properties of liquid nickel and iron," Phys. Rev. B 55(13), 8201-8206 (1997).
${ }^{29}$ B. J. McBride, S. Gordon, and M. A. Reno, "Thermodynamic data for fifty reference elements," Nasa Technical Paper No. TP-3287, 1993.

${ }^{30}$ C. Y. Ho, R. W. Powell, and P. E. Liley, "Thermal conductivity of the elements," J. Phys. Chem. Ref. Data 1, 279-442 (1972).

${ }^{31}$ F. L. Yaggee, E. R. Gilbert, and J. W. Styles, "Thermal expansivities, thermal conductivities, and densities of vanadium, titanium, chromium and some vanadium-base alloys (a comparison with austenitic stainless steel)," J. Less-Common Met. 19(1), 39-51 (1969).

${ }^{32}$ H. D. Erfling, "Studien zur thermischen Ausdehnung fester Stoffe in tiefer Temperatur. III (Ca, Nb, Th, V, Si, Ti, Zr)," Annalen der Physik 433(6), 467-475 (1942)

${ }^{33}$ D. I. Bolef, R. E. Smith, and J. G. Miller, "Elastic properties of vanadium. I. Temperature dependence of elastic constants and thermal expansion," Phys. Rev. B 3(12), 4100-4110 (1971).

${ }^{34}$ P. F. Paradis, T. Ishikawa, and S. Yoda, "Non-contact measurements of surface tension and viscosity of niobium, zirconium, and titanium using an electrostatic levitation furnace," Int. J. Thermophys. 23(3), 825-842 (2002).

${ }^{35}$ P. Hidnert and H. S. Krider, "Thermal expansion of columbium," Bur. Stand. J. Res. 11, 279-284 (1933).

${ }^{36}$ A. Cezairliyan and A. P. Miiller, "A transient (subsecond) technique for measuring heat of fusion of metals," Int. J. Thermophys. 1(2), 195-216 (1980).

${ }^{37}$ F. Righini, R. B. Roberts, and A. Rosso, "Thermal expansion by a pulseheating method: Theory and experimental apparatus," High Temp.-High Press. 18(5), 561-571 (1986).

${ }^{38}$ A. G. Worthing, "Physical properties of well seasoned molybdenum and tantalum as a function of temperature," Phys. Rev. 28(1), 190-201 (1926).

${ }^{39}$ F. C. Nix and D. MacNair, "The thermal expansion of pure metals II: molybdenum, palladium, silver, tantalum, tungsten, platinum, and lead," Phys. Rev. 61, 74-78 (1942).

${ }^{40}$ J. L. McClure and A. Cezairliyan, "Measurement of the heat of fusion of tungsten by a microsecond-resolution transient technique," Int. J. Thermophys. 14(3), 449-455 (1993).

${ }^{41}$ G. K. White and S. J. Collocott, "Heat capacity of reference materials: $\mathrm{Cu}$ and W,” J. Phys. Chem. Ref. Data 13(4), 1251-1257 (1984).

${ }^{42}$ G. K. White and R. B. Roberts, "Thermal expansion of reference materials: Tungsten and $\alpha-\mathrm{Al}_{2} \mathrm{O}_{3}$," High Temp.-High Press. 15(3), 321-328 (1983).

${ }^{43}$ R. K. Kirby, "Thermal expansion of tungsten from 293 to $1800 \mathrm{~K}$," High Temp.-High Press. 4(4), 459-462 (1972).

${ }^{44}$ J. L. McClure and A. Cezairliyan, "Measurement of the heat of fusion of tantalum by a microsecond-resolution transient technique," Int. J. Thermophys. 15(3), 505-511 (1994). 